\title{
Diagnóstico da Gestão do Uso Público no Parque Estadual do Guartelá, Paraná
}

Barbara Nogueira1 , Maurício Savi ${ }^{2}$, Fernanda Moura Fonseca Lucas ${ }^{1}$, Mariana Meira Micaloski ${ }^{1}$ \& Pâmela Christina da Silva ${ }^{3}$

Recebido em 27/04/2020 - Aceito em 08/09/2020

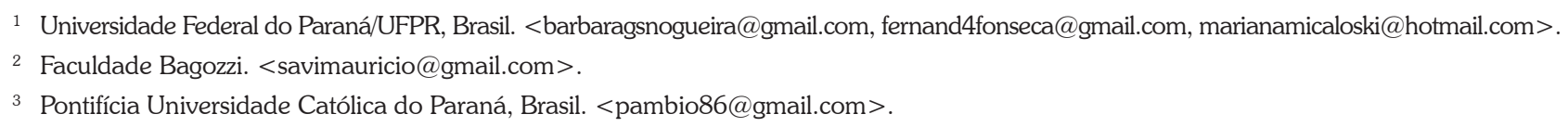

RESUMO - O uso público em unidades de conservação brasileiras é considerado um instrumento estratégico para a aprendizagem e incentivo da conservação da natureza, já que a abertura e a adequada gestão dessas áreas possibilitam sua aproximação com a sociedade. Porém, essas atividades possuem uma complexidade de fatores sociais e ambientais. $\mathrm{O}$ objetivo desta pesquisa foi realizar o diagnóstico da gestão do uso público do Parque Estadual do Guartelá, localizado em Tibagi/PR. O trabalho foi elaborado com base na adaptação dos princípios indicados no Roteiro Metodológico para Impactos da Visitação, produzido pelo Instituto Chico Mendes de Conservação da Biodiversidade, e na sistematização de informações contidas em fichas de cadastro de visitantes. Observou-se que, no período de 2007 a 2016, a área recebeu um total de 175.338 pessoas, apresentando uma média de 17.533 por ano, sendo que $94,60 \%$ da demanda de visitantes concentra-se em apenas um atrativo. A caracterização da gestão da visitação da unidade mostrou uma ausência de monitoramento sistematizado decorrente da falta de dados básicos, como tipificação da experiência e satisfação do usuário, de modo a fragilizar as ações de manejo.

Palavras-chave: Áreas naturais protegidas; ecoturismo; socioambiental.

\section{Diagnosis Management for Public Use in Guartelá State Park, Paraná}

\begin{abstract}
Public use in brazilian conservation units is considered a strategic tool for learning and encouraging nature conservation, since the opening and proper management of these areas, it is possible to get closer to society. However, these activities have a complexity of social and environmental factors. The objective of the research was to diagnose the management of public use in the Guartelá State Park, located in Tibagi/PR. The work was based on the adaptation of the principles indicated in the Methodological Roadmap for Impacts of Visitation, produced by the Chico Mendes Institute for Biodiversity Conservation, and the systematization of information contained in visitor registration forms. It was observed that in the period 2007 to 2016, the area received 175.338 people, with an average of 17.533 per year, and $94.60 \%$ of visitor demand is concentrated in only one attraction. The survey of the characterization of the current management of public use of the unit showed an absence of systematic monitoring due to the lack of basic data, such as typification of the experience and user satisfaction, to weaken management actions.
\end{abstract}

Keywords: Protected natural areas; ecotourism; social and environmental.

\section{Diagnóstico de la Gestión del Uso Público en el Parque Estatal Guartelá, Paraná}

RESUMEN - El uso público en unidades de conservación brasileñas es considerado un instrumento estratégico para el aprendizaje e incentivo de la conservación de la naturaleza, ya que la apertura y la adecuada gestión de esas áreas posibilitan acercar con la sociedad. Sin embargo, estas actividades tienen una complejidad de factores sociales y ambientales. El objetivo de la investigación fue 
diagnosticar el manejo de uso público en el Parque Estatal Guartelá, ubicado en Tibagi/PR. La labor se basó en la adaptación de los principios indicados en la Hoja de Ruta Metodológica para los Impactos de las Visitas, elaborada por el Instituto Chico Mendes para la Conservación de la Biodiversidad, y en la sistematización de la información contenida en los formularios de registro de visitantes. Se observó que en el período de 2007 a 2016, la zona recibió un total de 175.338 personas, con un promedio de 17.533 por año. Sin enbargo, el $94,60 \%$ de la demanda de visitantes se concentra en una sola atracción. La encuesta de caracterización de la gestión actual del uso público de la unidad mostró una ausencia de vigilancia sistemática debido a la falta de datos básicos, como una tipificación de la experiencia y la satisfacción del usuario, debilitando así las acciones de gestión.

Palabras clave: Áreas naturales protegidas; ecoturismo; socioambiental.

\section{Introdução}

O estado do Paraná é formado por uma diversa composição fitogeográfica, que originalmente apresentava $83 \%$ do seu território coberto por florestas, cerca de $17 \%$ intervalados entre campos naturais e enclaves de cerrado (Roderjan et al. 2002, Pires et al. 2012). Atualmente, com a histórica e contínua interferência antrópica, somada ao uso predatório dos recursos naturais, a vegetação original foi reduzida a, aproximadamente, 10\%. Destacam-se nesse lamentável cenário as florestas ombrófilas mistas e os campos naturais, com menos de $1 \%$ de suas áreas de ocorrência. Dessa forma, torna-se imprescindível a adoção de incentivos e políticas públicas para conservação dos recursos naturais (Wrege et al. 2017, Adenesky Filho et al. 2018).

De acordo com a Convenção da Diversidade Biológica (Brasil 1994), um dos principais métodos para manutenção adequada dos ecossistemas é a criação de áreas protegidas. No Brasil, uma das modalidades de áreas protegidas são as unidades de conservação, que são conceituadas e ordenadas pela Lei Federal n ${ }^{\circ}$ 9.985/2000, que estabelece o Sistema Nacional de Unidades de Conservação (SNUC). No estado do Paraná, em virtude do cenário de degradação ambiental, as unidades de conservação também se apresentam como fundamentais para manutenção e proteção dos remanescentes vegetacionais, desempenhando função ecológica e contribuindo para o desenvolvimento econômico e social (Pires et al. 2012).

As unidades de conservação que compõem o SNUC estão divididas em dois grupos: proteção integral e uso sustentável. Nas unidades de conservação de proteção integral é admitido apenas o uso indireto dos recursos naturais; enquanto nas unidades de conservação de uso sustentável deve-se compatibilizar a conservação da natureza com o adequado uso dos recursos naturais (Brasil 2000).

Nas unidades de conservação de proteção integral, a categoria "parque" é a mais conhecida e procurada no Brasil, ocorrendo o aumento dessa demanda anualmente (ICMBio 2019). Dentro dos objetivos dos parques, destaca-se o uso público por meio da visitação ordenada, que é considerado um instrumento estratégico para a aprendizagem $e$ incentivo na conservação da natureza (MMA 2006, Kabashima \& Magro 2011). A adequada gestão dessas áreas possibilita a aproximação com a sociedade, oferece visibilidade e contribui para alcançar seus objetivos e ajudar no desenvolvimento das regiões em que estão inseridas (Takahashi 2004).

As atividades de visitação possuem uma complexidade de fatores sociais em ambientes de fragilidade ambiental que podem causar diferentes impactos quando não manejados de forma adequada, sobretudo na ausência ou má utilização do plano de manejo, que se constitui na principal ferramenta de orientação administrativa e técnica dessas áreas. As unidades de conservação, embora desempenhem importantes serviços para a conservação dos recursos naturais brasileiros, enfrentam inúmeros desafios na implementação do SNUC, e a falta de investimento é a maior causa desses problemas (Medeiros et al. 2011). Para buscar o manejo e a resolução dos conflitos ambientais, se faz necessária a adoção de técnicas que facilitem esse caminho; essas técnicas são ferramentas de suma importância para avaliar os impactos oriundos das atratividades desenvolvidas nessas áreas (Costa \& Mello 2005).

A busca da definição de indicadores de impactos recreativos, ecológicos e sociais contribui para o aprimoramento do manejo dessas áreas, sendo os passos fundamentais no planejamento $e$ 
gestão dos recursos naturais e culturais. Além disso, por meio do conhecimento das características e expectativas dos usuários, é possível melhorar os níveis de comunicação, bem como servir de subsídio para alcançar melhorias e eficiência no manejo da visitação (Takahashi 1998, Milano 2004, Nelson 2012).

Diante desse cenário e da crescente pressão por atividades ao ar livre, há necessidade de buscar informações que contribuam para o planejamento do uso público. Assim, o presente trabalho tem como objetivo realizar um diagnóstico da visitação no Parque Estadual do Guartelá, situado no município de Tibagi/PR.

\section{Material e Métodos}

\section{Caracterização da área de estudo}

O Parque Estadual do Guartelá (PEG) foi criado em 1992, por meio do Decreto Estadual n 1.229, com área de 4.389,88ha (Paraná 1992). No entanto, em 24 de setembro de 1996, o Decreto Estadual n 2.329 reduziu a área que, atualmente, apresenta 798,97ha. Situado no município de Tibagi, segundo planalto paranaense, está inserido na Escarpa Devoniana sob a unidade geológica denominada Grupo Itararé. Sobre sedimentos de origem glacial (diamictitos) iniciou-se a deposição dos conglomerados e arenitos esbranquiçados da Formação Furnas, de origem marinha e costeira, formando as paredes do Canyon Guartelá, que é a principal atração dessa unidade de conservação (IAP 2002).

A área está inclusa no bioma da Mata Atlântica, sendo caracterizada por uma diversidade de composições fitogeográficas, que, de acordo com Veloso et al. (1991), são as estepes gramíneolenhosas, savana arborizada e a floresta ombrófila mista. Segundo a classificação de Köppen, a área apresenta clima $\mathrm{Cfa}$ - subtropical úmido quente, com influência direta do clima $\mathrm{Cfb}$ - temperado sempre úmido (Aparecido et al. 2016).

Essa área é considerada importante atrativo turístico desde os meados de 1980. É frequentada por excursionistas que associam o turismo de aventura com a contemplação da paisagem. Desde sua criação, o PEG foi alvo de impactos ambientais causados por um longo período de visitas desordenadas, além de ter sofrido com a caça e pesca predatória praticadas em seu interior. Atualmente, o plano de manejo estabelece que o horário de abertura à visitação pública é das $9 \mathrm{~h}$ às $16 \mathrm{~h}$, de quarta a segunda-feira, inclusive nos feriados (IAP 2002). O espaço destinado para uso público corresponde a $5,18 \%$ da área total do parque, sendo $3,80 \%$ na zona de uso extensivo e $1,38 \%$ na de uso intensivo (Figura 1 ).

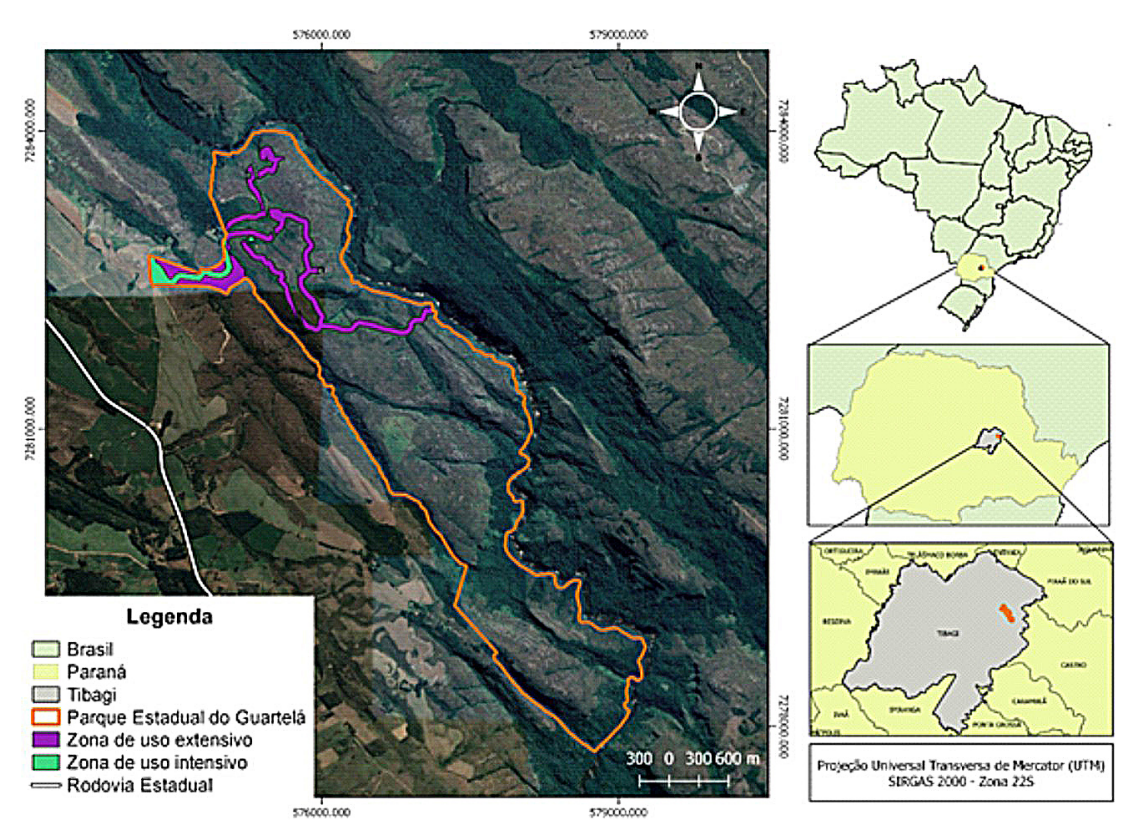

Figura 1 - Mapa de localização do Parque Estadual do Guartelá,Tibagi/PR. 


\section{Obtenção e análise dos dados}

O Roteiro Metodológico para Impactos da Visitação (ICMBio 2011) foi utilizado como base para a elaboração do diagnóstico do uso público no Parque Estadual do Guartelá. Esse guia foi publicado pelo Instituto Chico Mendes de Conservação da Biodiversidade no intuito de propor um marco de procedimentos comuns que orientassem o manejo e o monitoramento nos parques. Os elementos pesquisados foram adaptados, seguindo as etapas sugeridas (Figura 2). Todavia, as etapas 4 e 5 não foram executadas, devido à ausência dos indicadores de monitoramento dos atrativos da unidade de conservação $e$, consequentemente, não se abordou a avaliação de ações de manejo.

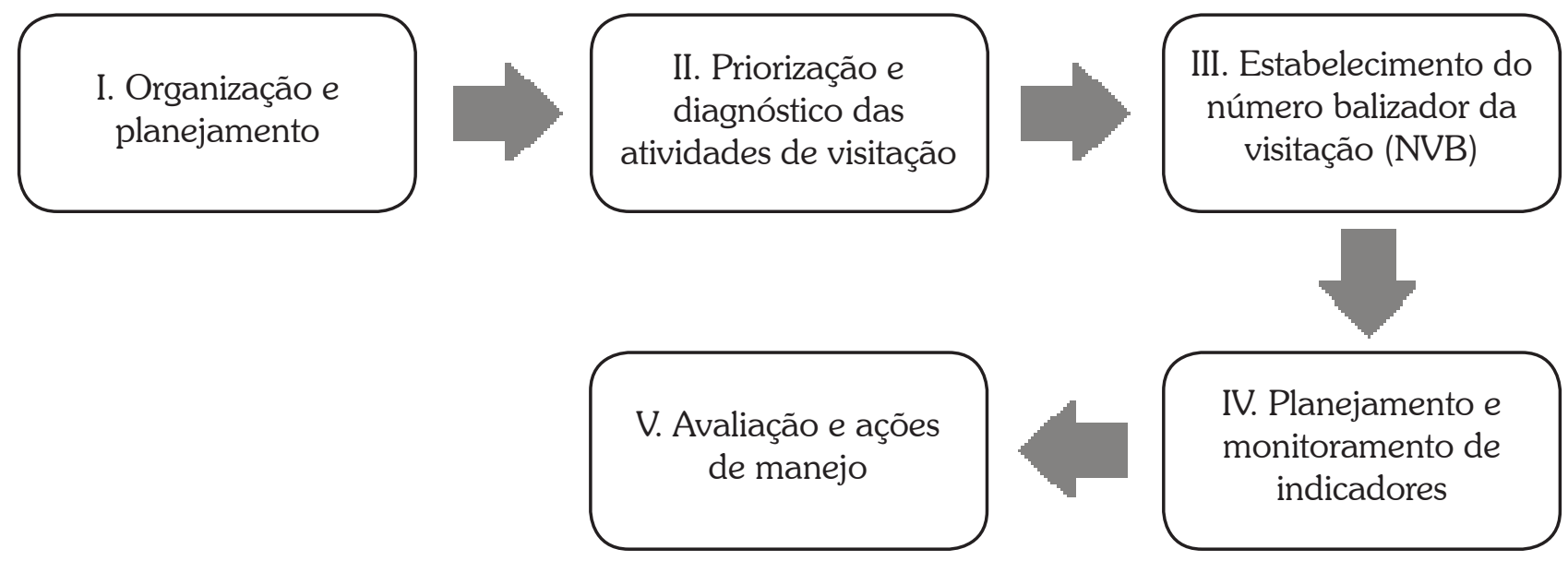

Figura 2 - Ciclo do manejo de impactos.

Adaptado de: ICMBio (2011).

O levantamento ocorreu a partir de dados coletados e disponibilizados pelo órgão gestor, enquanto a adaptação do Roteiro ordenou o processo investigativo de identificação das lacunas. Sendo assim, a etapa 1 consistiu em pesquisa documental de informações disponíveis em: i) dados públicos encontrados em sítios eletrônicos: decretos de criação, plano de manejo, programa de uso público, número total de visitantes por mês e ano; ii) ficha de cadastro de visitantes: materiais solicitados por meio de autorização de pesquisa ( $\mathrm{n}^{\circ} 33.15$ ) para os anos de 2014, 2015 e 2016.

Esses conhecimentos da etapa anterior orientaram a elaboração de uma entrevista semiestruturada e do roteiro para coleta de dados em campo, servindo de subsídio para a execução da etapa 2. Nessa fase, o objetivo foi descrever e identificar atrativos que necessitassem de ações de manejo. As pesquisas semiestruturadas podem ser caracterizadas por um conjunto de perguntas que foram levantadas previamente, permitindo um maior direcionamento do tema durante o processo de entrevista (Boni \& Quaresma 2005).
A etapa 3, na proposta do Roteiro Metodológico, é estabelecer o Número Balizador da Visitação (NBV), que busca estimar o número de visitantes que uma área específica suporta receber. Contudo, o NBV não é fixo e deve ser utilizado nas situações em que o controle de usuários é realizado, sendo uma ferramenta de apoio, com caráter dinâmico, já que as condições de manejo se alteram constantemente. A equação matemática desse procedimento utiliza dados básicos referentes a extensão $e$ tamanho do atrativo, como também o tempo disponível e aproximado para a realização do percurso. A obtenção das informações de campo, conjuntamente à entrevista, possibilita construir os indicadores numéricos que subsidiam o NBV.

\section{Resultados e Discussão}

No período de 2007 a 2016, o Parque Estadual do Guartelá recebeu um total de 175.338 visitantes, apresentando uma média de 17.533 por ano (Figura 3). Esses números colocam o PEG entre os cinco mais visitados do estado. 


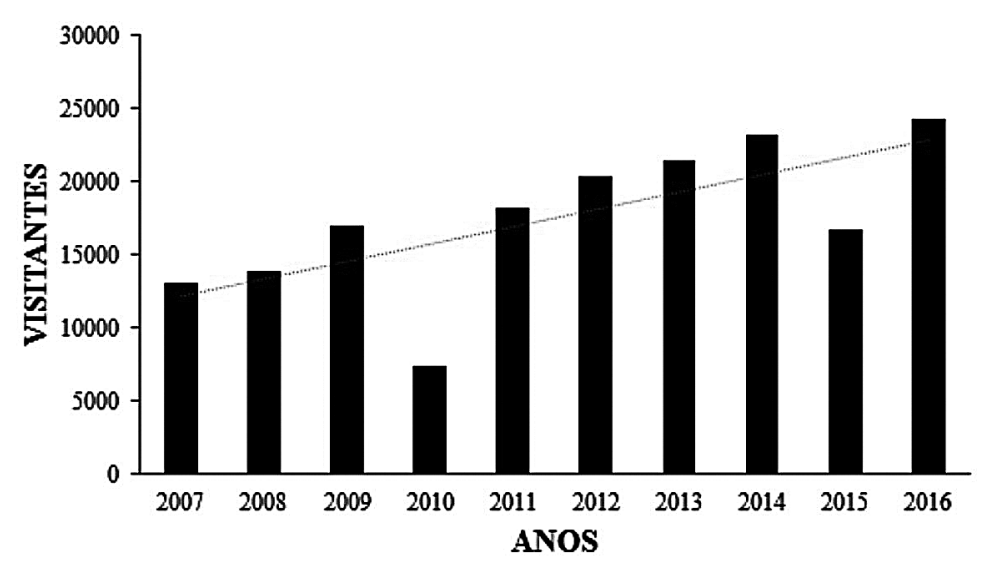

Figura 3 - Total de visitantes para cada ano, de 2007 a 2016, no Parque Estadual do Guartelá, Tibagi/PR.

Nota-se uma tendência crescente $e$ significativa no número de visitantes; porém, os anos de 2010 e 2015 apresentam inconstância na evolução devido à ausência de tabulação de dados de seis e três meses, respectivamente. Em relação ao aumento, um dos fatores desse impulso foi a implementação do Programa Parque Escola, criado em parceria com as Secretarias Estaduais de Educação e do Meio Ambiente, com o objetivo de incentivar a aproximação de escolas públicas, promovendo o conhecimento e a valorização da biodiversidade paranaense. Destaca-se a necessidade de inserção desse tipo de programa, uma vez que a educação ambiental, aliada a unidades de conservação, é um grande instrumento para promoção da conservação $e$ sustentabilidade dos recursos naturais (Madeira et al. 2018). Esse programa possibilitou que estudantes e seus familiares visitassem o PEG no período de 2011 a 2016, mas a carência de recursos financeiros levou ao seu encerramento de forma precoce (Nogueira 2017).

Para identificar o fluxo de visitantes por mês, optou-se por visualizar a média mensal de visitantes para os anos avaliados (Figura 4).

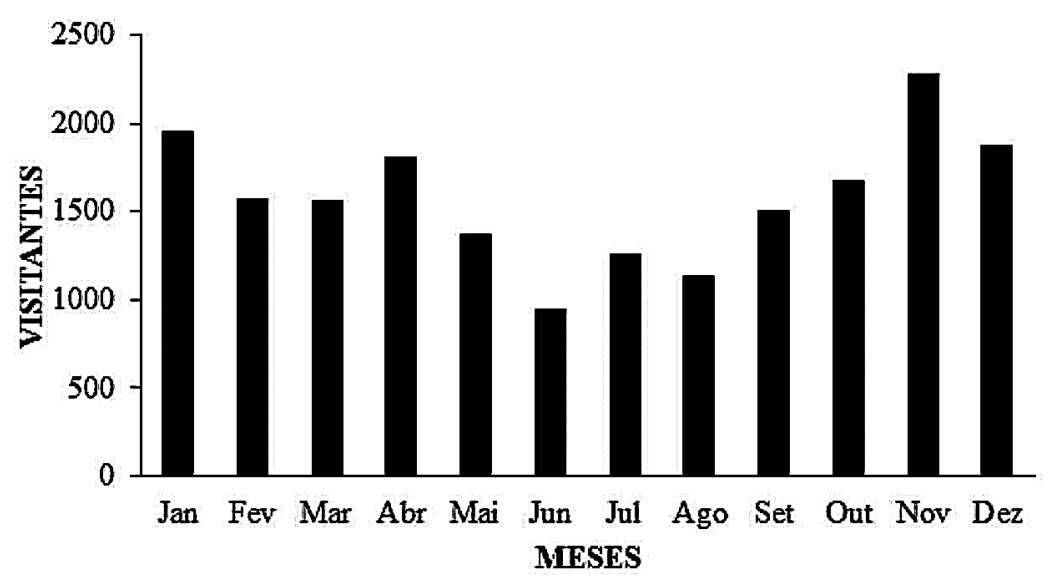

Figura 4 - Média de visitantes por mês, de 2007 a 2016, no Parque Estadual do Guartelá, Tibagi/PR.

Ao verificar a média de visitantes para os meses do ano, o gráfico demonstra queda em junho, julho e agosto, o que corresponde aos meses mais frios na região. Todavia, a visitação tem propensão a crescer nos meses mais quentes, sendo eles novembro, dezembro e janeiro. Essas informações contribuem para compreender a dinâmica de sazonalidade dos usuários e as possíveis medidas de gestão a serem implementadas. 
Em relação à ficha de cadastro de visitantes, a solicitação de pesquisa foi atendida parcialmente pelo órgão gestor, com a ausência de dados para os anos 2014 e 2015. Dessa forma, houve a caracterização da visita utilizando o ano 2016 como referência.

Com as informações analisadas, foi possível verificar o equilíbrio de gêneros, sendo que $49,8 \%$ dos visitantes se declaram como homens e 50,2 \% mulheres. Esse resultado pode ser comparado à pesquisa sobre planejamento turístico de Silva \& Silva (2014) no PEG, que apresenta pequena variação desse percentual, do qual $54 \%$ são mulheres e $46 \%$ homens.

Em relação à faixa etária dos visitantes, estes apresentam perfil adulto, correspondendo a $60 \%$ da visitação total, que está dividida em dois grupos principais: os de 21 a 30 anos, com 26,01\%; e os de 31 a 50 anos, com 33,86\% (Figura 5).

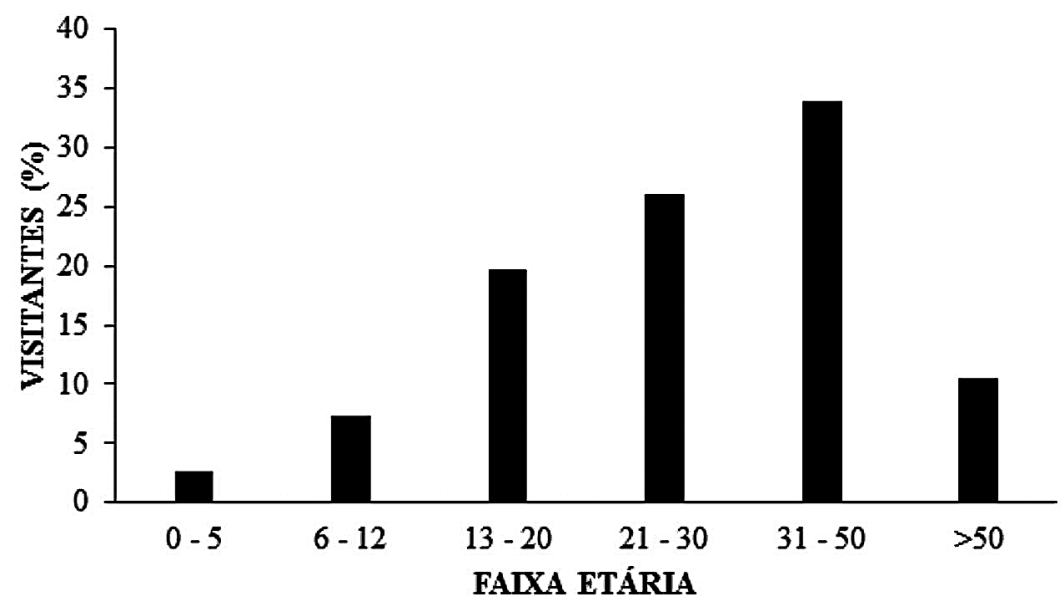

Figura 5 - Distribuição de faixa etária correspondente aos visitantes que frequentaram o Parque Estadual do Guartelá, Tibagi/PR, em 2016.

Cabe mencionar que o ordenamento do intervalo de faixa etária é realizado pelo próprio órgão gestor. Isso impossibilita a visualização das informações utilizando o mesmo espaço de tempo entre as idades. Outro trabalho sobre visitação em área protegida do Paraná, realizado no Parque Estadual de Vila Velha, apresentou o mesmo formato de informações (Nogueira et al. 2017).

No critério origem da visitação, há um predomínio de paranaenses oriundos dos municípios de Curitiba e Ponta Grossa. Também foi observado que uma parcela dos visitantes interestaduais são oriundos principalmente de São Paulo, Santa Catarina e Rio Grande do Sul (Figura 6). Silva \& Silva (2014) observaram que turistas provenientes de Santa Catarina e do Rio Grande do Sul possuem representatividade na visitação do $\mathrm{PEG}$ devido à proximidade geográfica e maior disponibilidade de informações turísticas regionais.
O carro é a principal forma de locomoção (66,53\%), seguido dos ônibus de excursão $(20,23 \%)$ e ônibus escolares $(4,18 \%)$. Outros meios de transporte, como van, moto $e$ bicicleta, correspondem a $9,06 \%$ das respostas. Considerando esses números, fica evidente a necessária manutenção e sinalização das estradas, tanto as principais como as vicinais.

A partir dos levantamentos da etapa 1, foi possível aplicar a metodologia referente à segunda etapa (priorização e diagnóstico), com a visita in loco e entrevista com o gestor da unidade de conservação. Houve investigação da infraestrutura existente, número de funcionários, lacunas, parcerias e aplicabilidade dos programas de manejo, assim como a organização para o monitoramento do uso público, demostrando elevada carência nessas ações.

Foi verificado que o cadastro é utilizado de forma simplista, somente na obtenção do 


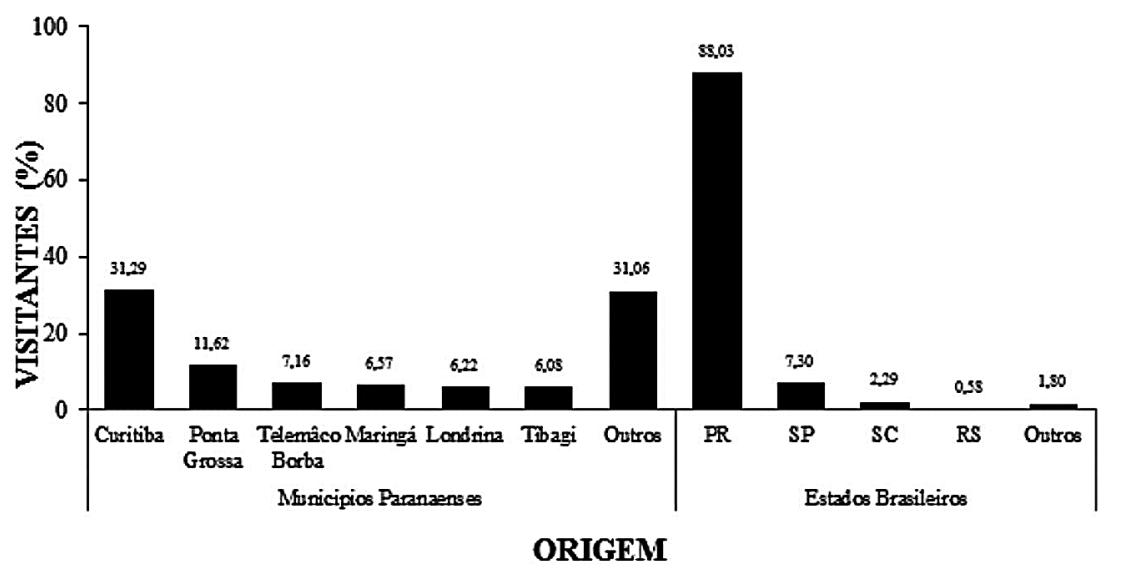

Figura 6 - Local de origem dos visitantes que frequentaram o Parque Estadual do Guartelá, Tibagi/PR em 2016.

número total de visitantes. Outra vulnerabilidade é a abordagem, pois informações e normas são repassadas de forma oral ou em painéis complementares. Os executores dessas funções são os funcionários terceirizados, grupo de servidores com elevada rotatividade de atuação. Ao coletar sistematicamente dados sobre expectativa, experiência e satisfação dos usuários, essas informações permitem melhorar a aplicação dos recursos humanos e financeiros. Outro ponto relevante é o auxílio na adoção e apoio de pesquisas que subsidiem estratégias para uma melhor execução do manejo no atendimento das demandas de uso público.

Neste diagnóstico foi constatado que não há funcionários específicos para atender às demandas do uso público, priorizando a empregabilidade na manutenção das infraestruturas e aspectos gerais da área de visitação. Há três profissionais do estado e oito terceirizados, cuja atuação é dividida entre um jardineiro, um operador de máquina costal, um auxiliar de serviços gerais, um servente e quatro porteiros. Dentro das respostas coletadas junto à gestão da unidade de conservação, foi reconhecida a insatisfatória implementação do plano de manejo, devido à ausência de recursos financeiros $e$ humanos. A carência de recursos humanos é um dos principais problemas relatados em outras unidades de conservação (Alves et al. 2010). Para dirimir a escassa mão de obra, as alternativas utilizadas foram o auxílio de voluntários e os funcionários cedidos pela Secretaria de Turismo de Tibagi.

Existem outras instituições, como as de ensino (universidades e escolas técnicas), que também auxiliam no desenvolvimento do parque, por meio de aulas de campo e estudos científicos e práticos. Em Ponta Grossa, os colégios profissionalizantes possuem agenda de visitação que repassam previamente para o gestor essa atividade. Destaca-se que o PEG não possui conselho gestor consolidado, ferramenta de gestão que poderia auxiliar e colaborar para a minimização de suas vulnerabilidades.

A unidade de conservação apresenta somente dois atrativos abertos para visitação, podendo esta ser realizada de forma autônoma, conduzida ou monitorada. Durante o processo de campo, constatou-se a demanda de visitantes, impactos evidentes e caraterísticas da visita (Tabela 1).

No Roteiro Metodológico para Impactos da Visitação (ICMBio 2011), a intensidade de demanda refere-se à procura pela visita em determinado atrativo e, caso esta seja maior que $70 \%$, é considerada alta. No caso do PEG, que potencializa e concentra mais de $90 \%$ em um único atrativo, a situação merece atenção, no intuito de compreender e apontar estratégias de mitigação dos impactos evidentes dessa visitação concentrada.

De modo proposital ocorre a não sinalização da Trilha Formações Ruiniformes. A gestão da unidade de conservação busca diminuir a demanda por esse atrativo, devido aos danos em local com maior vulnerabilidade ambiental $e$ arqueológica. A medida foi adotada como forma de potencializar o controle dos visitantes, uma vez que os interessados em conhecer esse ambiente terão que realizar agendamento com guia de uma 
Tabela 1 - Atrativos do Parque Estadual do Guartelá, Tibagi/PR, e suas respectivas intensidades de demanda, zoneamento e características.

\begin{tabular}{|c|c|c|c|c|}
\hline Atrativos & $\begin{array}{c}\text { Demanda dos } \\
\text { visitantes }\end{array}$ & Impactos evidentes & $\begin{array}{c}\text { Zona em que } \\
\text { se localiza }\end{array}$ & Características \\
\hline $\begin{array}{c}\text { Trilha Básica - } \\
\text { acesso ao Mirante } \\
\text { do Cânyon }\end{array}$ & $94,60 \%$ & $\begin{array}{c}\text { Processos erosivos, } \\
\text { desmatamento e mudanças } \\
\text { nos cursos d'água }\end{array}$ & $\begin{array}{c}\text { Intensivo } \\
\text { acesso para o Mirante do Parque pode ser } \\
\text { Sumidouro (piscinas naturais); capacidade de } \\
\text { carga: } 170 \text { pessoas/dia }\end{array}$ \\
\hline $\begin{array}{c}\text { Trilha Formações } \\
\text { Ruiniformes }\end{array}$ & $5,40 \%$ & Pisoteio & Intensivo & $\begin{array}{c}\text { Visitas apenas por agendamento com agências de } \\
\text { turismo da região; } 40 \text { visitantes/dia, divididos em } \\
\text { quatro grupos de } 10, \text { com horários estabelecidos }\end{array}$ \\
\hline
\end{tabular}

operadora local. Outra decisão foi pela ausência de placa informativa na entrada da trilha, no intuito de evitar visitação espontânea massiva.

Com base nas características reconhecidas no período de campo, foi colocada em prática a etapa 3, correspondente ao NBV. Sabendo que o parque permanece aberto das $9 \mathrm{~h}$ às $16 \mathrm{~h} 30$, e que para percorrer a trilha que dá acesso ao canyon necessita-se de duas horas para ir e voltar, mais 30 minutos de contemplação no mirante, foram consideradas as seguintes condições relativas ao atrativo Trilha Básica (Tabela 3):

Tabela 3 - Cálculo do número de vezes que as pessoas podem visitar o atrativo Trilha Básica em um dia.

\begin{tabular}{|c|c|c|c|}
\hline $\begin{array}{c}\text { Fatores limitantes de } \\
\text { manejo }\end{array}$ & $\begin{array}{c}\text { Tempo oferecido } \\
\text { pela UC }\end{array}$ & $\begin{array}{c}\text { Tempo } \\
\text { necessário }\end{array}$ & $\begin{array}{c}\text { (NV) no de vezes que um grupo tem } \\
\text { condiçóes de visitar o local em um dia }\end{array}$ \\
\hline $\begin{array}{c}\text { Metragem do percurso }- \\
2.752 \mathrm{~m} \text { ida e volta }\end{array}$ & $7: 30$ & $2: 00$ & 4 \\
\hline $\begin{array}{c}\text { Espaço disponível no } \\
\text { mirante-20m }\end{array}$ & $5: 30$ & $0: 30$ & 17 \\
\hline
\end{tabular}

Com o valor de NV, calculou-se o NBV. Esse cálculo levou em conta que cada visitante necessita de $2 \mathrm{~m}^{2}$ na trilha e $1 \mathrm{~m}$ linear na área de visualização do mirante (Tabela 4).

Tabela 4 - Cálculo do NBV da caminhada na trilha e observação da paisagem no mirante do canyon.

\begin{tabular}{|c|c|c|c|c|}
\hline $\begin{array}{c}\text { Fatores limitantes } \\
\text { de manejo }\end{array}$ & NV & $\begin{array}{c}\text { D (disponibilidade } \\
\text { em áreas) }\end{array}$ & $\begin{array}{c}\text { N (necessidade por } \\
\text { pessoa) }\end{array}$ & Valor do fator \\
\hline Trilha & 4 & 1.376 & 2 & 2.752 \\
\hline Mirante & 17 & 20 & 1 & 340 \\
\hline
\end{tabular}

Para a Trilha Básica, o fator condicionante do NBV é o espaço disponível na parada do mirante, ou seja, 340 pessoas - estimativa feita a partir da média de permanência dos visitantes. $\mathrm{O}$ número balizador de pessoas que o espaço pode acomodar simultaneamente é de 20 pessoas.
É importante observar que a aplicação dessa referência só é viável quando é possível controlar a quantidade de usuários.

A pouca disponibilidade de atrativos em unidades de conservação também foi observada 
em um estudo realizado por Bellinassi et al. (2011), que avaliou como a visitação era estruturada em oito parques estaduais de São Paulo e cinco parques nacionais. Os resultados demonstraram o foco do uso público em trilhas interpretativas, apontando a pouca diversidade nas atividades e como esse fator poderia ajudar no aumento do interesse da população em contribuir para a conservação.

De acordo com a amostragem obtida, é possível visualizar características gerais da visitação, de modo a comparar com outras unidades de conservação e para adotar linhas próprias de manejo. Entretanto, para o estabelecimento $e$ monitoramento de indicadores sociais $e$ ambientais, é necessária a execução de atividades sistemáticas e cíclicas de acompanhamento dos elementos selecionados como "indicadores" de determinadas situações.

A respeito da ferramenta, cabe mencionar um diagnóstico realizado sobre a gestão das unidades de conservação mineiras, no qual os gerentes entrevistados citam que o monitoramento cíclico por meio de indicadores favorece o avanço do sistema, mas existe uma dificuldade em inserir a cultura de planejamento e avaliação dentro dos órgãos (Alves et al. 2010).

O monitoramento de diferentes fatores (erosão, resíduos, sons, depredação, danos a vegetação, afugentamento da fauna, incidência de fogo, entre outros) pode contribuir para aumentar ou limitar o uso nos atrativos (Cleckner \& Buck 1993, Schelhas 1993, Barros 2003, Lobo \& Simão 2011, Menezes 2014).

O parque não aplica ferramentas específicas de monitoramento, sendo que o acompanhamento é realizado de forma pontual e não sistematizada. Em estudo realizado nos Parques Nacionais do Caparaó (ES e MG), da Serra dos Órgãos (RJ) e Chapada dos Veadeiros (GO), Zimmermann (2006) também identificou a não utilização de técnicas para o monitoramento de impactos. Da mesma forma, Nogueira (2017) e Micaloski (2017) comprovaram a ausência de práticas complementares para subsidiar o manejo dos usuários nos Parques Estaduais do Cerrado, Mata dos Godoy, Pico do Marumbi, Rio Guarani e do Monge, no Paraná.

Vale ressaltar que o Parque Estadual do Guartelá faz parte de um projeto que estuda o processo de concessão total ou parcial de áreas destinadas a uso público em unidades de conservação. A iniciativa foi aprovada por meio da Lei $n^{\circ} 19.913 / 2019$, a qual destaca importantes condicionantes, como a valorização da população do entorno no processo. Sendo assim, além de monitorar o aspecto biofísico, esses dados podem contribuir para entender as demandas inerentes ao desenvolvimento local e regional, levando em consideração os diversos atores sociais que compõem o território.

Garcia et al. (2018) apontam que, para gerir unidades de conservação, é preciso compreender a dinâmica do território. A paisagem não é estática, e parte dela é resultado do processo de interação entre homem e natureza. Por isso, a visitação deve contribuir para fomentar o sentimento de pertencimento ao ambiente e o vínculo afetivo. O uso público atua como um subsistema que auxilia o todo de uma área; entender o perfil e a percepção dos atores ajuda na implementação dos parques.

O planejamento e a gestão do uso público é assunto recente no Brasil, sendo necessário um esforço em pesquisas, reflexões e trocas de experiências (Vallejo 2013). Assim como o estudo publicado por Andrade et al. (2020), que demonstra que a interlocução entre pesquisadores, gestores e guias locais pode proporcionar avanço na estruturação da qualidade das informações $e$ subsídio para organizar a gestão do uso público. Além disso, destaca-se que parques estaduais são os que mais carecem de informações publicadas e disponíveis (Canto-Silva \& Silva 2017).

\section{Conclusão}

O Roteiro Metodológico para Impactos da Visitação, ferramenta que contribuiu para o diagnóstico do uso público no Parque Estadual do Guartelá, promoveu o levantamento da caracterização da atual gestão da visitação na UC. Entretanto, a ausência de monitoramento sistematizado com indicadores de impactos está relacionada a lacunas decorrentes da falta de dados básicos, como o adequado preenchimento do cadastro de visitantes e o conhecimento sobre a percepção e experiência dos visitantes da unidade de conservação. A inexistência de ferramentas para realizar o manejo da visitação implica a intensificação dos impactos, já que não há compreensão da dinâmica dos eventos e suas relações. 
Sendo assim, uma forma de mitigar essa lacuna são as parcerias com instituições de ensino para a organização, implementação e sistematização de uma base de dados. Além de contribuir para a aplicação de ferramentas científicas de avaliação da experiência e expectativa dos usuários, as pesquisas também auxiliam na mobilização de ações de comunicação $e$ cooperação para a unidade de conservação.

Recomenda-se a realização de pesquisas sobre características, percepções e experiências dos usuários. Com a devida amostragem, é possível estabelecer indicadores para monitoramento, bem como visualizar estratégias para redução de impactos e potencialização de práticas conservacionistas, de modo a subsidiar o adequado manejo do uso público da unidade.

\section{Referências Bibliográficas}

Adenesky Filho E, Valdris D, Schorn LA, Botosso PC \& Galvão F. 2018. Estrutura fitossociológica em uma zona de ecótono de Floresta Estacional Semidecidual e Floresta Ombrófila Mista, p. 80-82. In: Anais do Seminário Sul-brasileiro sobre a Sustentabilidade da Araucária: Uso sustentável, produção, inovação, educação, legislação, conservação.

Alves RG, Rezende JLP, Borges LAC, Fontes MAL \& Alves LWR. Análise da gestão das unidades de conservação do sistema estadual de áreas protegidas de Minas Gerais. Espaço \& Geografia, 13(1): 1-35, 2010.

Andrade TC, Souza TVSB \& Cunha AA. Estruturação do rol de oportunidades de visitação no Parque Nacional da Chapada dos Veadeiros (GO). Revista Brasileira de Ecoturismo, 13(2): 365-392, 2020.

Aparecido LEO, Rolim GS, Richetti J, Souza P \& Johann JA. Köppen, Thornthwaite and Camargo climate classifications for climatic zoning in the State of Paraná, Brazil. Rev. Ciência e Agrotecnologia, 40(4): 405-417, 2016.

Barros MIA. 2003. Caracterização da visitação, dos visitantes e avaliação dos impactos ecológicos $e$ recreativos do planalto do Parque Nacional do Itatiaia. Dissertação (Mestrado em Recursos Florestais). Universidade de São Paulo. 121p.

Bellinassi S, Pavão AC \& Cardoso-Leite E. Gestão e uso público de unidades de conservação: um olhar sobre os desafios e possibilidades. Revista Brasileira de Ecoturismo, 4(2): 274-293, 2011.

Brasil. Lei n ${ }^{\circ} 9.985$, de 18 de julho de 2000. Regulamenta o art. 225, $\S 1^{\circ}$, incisos I, II, III e VII da Constituição Federal, institui o Sistema Nacional de Unidades de Conservação da Natureza e dá outras providências.
Brasil. Decreto Legislativo $n^{\circ} 2$, de 1994. Aprova o texto sobre a Convenção sobre Diversidade Biológica, assinada durante a Conferência das Nações Unidas sobre Meio Ambiente e Desenvolvimento.

Boni V \& Quaresma SJ. Aprendendo a entrevistar: como fazer entrevistas em Ciências Sociais. Em tese (revista eletrônica), 2(1): 68-80, 2005.

Canto-Silva CR \& Silva JS. Panorama da visitação e da condução de visitantes em parques brasileiros. Revista Brasileira de Pesquisa em Turismo, 347-364, 2017.

Cleckner RM \& Buck R. Anatomia de una via para transito de bicicletas. Apunte 4c. In: Moore, Alan. Manual para la capacitación del personal de áreas protegidas. $2 \mathrm{v}$, Módulo F: Mantenimiento, Tema 4: Mantenimiento de senderos, caminos y carreteras. National Park Service. 1993.

Costa VC \& Mello FAP. 2005. Manejo e monitoramento de trilhas interpretativas: contribuição metodológica para a percepção do espaço ecoturístico em unidades de conservação, p. 8-10. In: Anais Simpósio Nacional sobre Geografia, Percepção e Cognição do Meio Ambiente.

Garcia LM, Moreira JC \& Burns R. Conceitos geográficos na gestão de unidades de conservação brasileiras. Geographia, v.20(48): 53-62, 2018. DOI: 10.22409/ GEOgraphia2018.v20i42.a13832.

Instituto Ambiental do Paraná (IAP). Plano de manejo do Parque Estadual do Guartelá, 2002.

Instituto Ambiental do Paraná (IAP), Número de visitantes nas unidades de conservação Paranaense, 2020. $<$ http://www.iap.pr.gov.br/modules/conteudo/conteudo. php? conteudo=1248> . Acesso em: 05/01/2020.

Instituto Chico Mendes de Conservação da Biodiversidade (ICMBio). 2011. Roteiro metodológico para manejo de impactos da visitação - com enfoque na experiência do visitante e na proteção dos recursos naturais e culturais. 88p.

Instituto Chico Mendes de Conservação da Biodiversidade (ICMBio). Visitação em Parque Nacionais bate novo recorde em 2018, Revista Biodiversa ICMBio, Brasília, ed. 10, fev. 2019.

Kabashima Y \& Magro TC. Caracterização atual do monitoramento de impactos de visitação em parques do estado de São Paulo. OLAM - Ciência \& Tecnologia, 11(2): 107-123, 2011.

Lobo AC \& Simão LL. 2011. Manual de monitoramento e gestão dos impactos da visitação em unidades de conservação. Fundação Florestal. WWFBRASIL.78p.

Madeira PA, Coelho MAP, Laureano RC, Cherigati WG. A importância da educação ambiental em unidades de conservação para promover a conscientização de turistas. Revista Mythos, 10(2): 24-31, 2018. DOI: 10.36674/mythos.v10i2.228. 
Ministério do Meio Ambiente (MMA). 2006. Diretrizes para visitação em unidades de conservação. Brasília: Ministério do Meio Ambiente. 70p.

Medeiros R, Young CEF, Pavese HB \& Araújo FFS. 2011. Contribuição das unidades de conservação brasileiras para a economia nacional: sumário executivo. UNEP - WCMP. 44p.

Menezes PC. 2014. Sinalização de trilhas: guia prático. $77 p$.

Micaloski MM. 2017. Uso público do Parque Estadual do Monge, Lapa - PR. Dissertação (Mestrado em Engenharia Florestal). Universidade Federal do Paraná. 90p.

Milano MS. 2004. Conceitos básicos e princípios gerais de planejamento, manejo e administração de áreas naturais protegidas. Curitiba: Fundação O Boticário de Proteção à Natureza. 74p.

Nelson SP. 2012. Uso público em unidades de conservação. p. 215-237. In: WWF - Brasil; Instituto Ipê. Gestão de Unidades de Conservação: Compartilhando uma experiência de capacitação. WWF - Brasil. 396p.

Nogueira BGS. 2017. A gestão da visitação em seis unidades de conservação no estado do Paraná. Dissertação (Mestrado em Engenharia Florestal). Universidade Federal do Paraná. 107p.

Nogueira BGS, Soares RV, Tetto AF, Vivekananda G \& Trento M. Perfil dos visitantes do Parque Estadual de Vila Velha, Paraná-Brasil. Revista Espacios, 17(38): 33, 2017.

Paraná. Decreto Estadual n 1.229 , de 27 de março de 1992. Dispõe sobre a criação do Parque Estadual do Guartelá.

Pires PTL, Zeni Junior DM \& Gaulke D. As unidades de conservação e a floresta ombrófila mista no estado do Paraná. Ciência Florestal, 22(3): 589-603, 2012.

Roderjan CV, Galvão F, Kuniyoshi YS \& Hatschback G. As unidades fitogeográficas do estado do Paraná. Ciência e Ambiente, 24: 75-92, 2002.
Schelhas J. 1993. Diseño, Construccion y mantenimiento de senderos. Apunte 4d. In: MOORE, Alan. Manual para la capacitación del personal de áreas protegidas. 2v, Módulo F: Mantenimiento, Tema 4: Mantenimiento de senderos, caminos y carreteras. Washington: National Park Service.

Secretaria do Estado de Meio Ambiente e Recursos Hídricos (SEMA). Parques do paraná, 2019.<http:// www.paranaprojetos.pr.gov.br/modules/conteudo/ conteudo.php?conteudo=41> Acesso em 11/12/2019.

Silva NP \& Silva NCG. A importância do planejamento para o desenvolvimento do turismo sustentável no Parque Estadual do Guartelá. Turismo - Visão e ação, 1(16): 167-185, 2014.

Takahashi LY. 1998. Caracterização dos visitantes, suas preferências e percepções e avaliação dos impactos da visitação pública em duas unidades de conservação do estado do Paraná. Tese (Doutorado em Ciências Florestais) - Setor de Ciências Agrárias, Universidade Federal do Paraná, 144p.

Takahashi LY. Uso público em unidades de conservação. Cadernos de Conservação, 4(30): 570-580, 2004.

Vallejo LR. Uso público em áreas protegidas: atores, impactos, diretrizes de planejamento e gestão. Anais - Uso público em unidades de conservação, Niterói, 1(1): 13-26, 2013.

Veloso HP, Rangel Filho ALR \& Lima JCA. 1991. Classificação da vegetação brasileira, adaptada a um sistema universal. IBGE - DERMA. 123p.

Wrege MS, Garrastazu MC, Soares MTS, Fritzsons E, SousaVA\&Aguiar AV. Principais fitofisionomias existentes no estado do Paraná e os novos cenários definidos pelas mudanças climáticas globais. Ambiência, 13(3): 600615, 2017 DOI:10.5935/ambiencia.2017.03.05.

Zimmermann A. 2006. Visitação nos parques nacionais brasileiros: um estudo à luz das experiências do Equador e da Argentina. Dissertação (Mestrado em Desenvolvimento Sustentável) - Centro de Desenvolvimento Sustentável, Universidade de Brasília. 278p.

\section{Biodiversidade Brasileira - BioBrasil. Fluxo Contínuo n. 3, 2020}

http://www.icmbio.gov.br/revistaeletronica/index.php/BioBR

Biodiversidade Brasileira é uma publicação eletrônica científica do Instituto Chico Mendes de

Conservação da Biodiversidade (ICMBio) que tem como objetivo fomentar a discussão e a disseminação de experiências em conservação e manejo, com foco em unidades de conservação $e$ espécies ameaçadas.

ISSN: 2236-2886 